\title{
Ex vivo buccal drug delivery of ropinirole hydrochloride in the presence of permeation enhancers: the effect of charge
}

Eleni Kontogiannidou, ${ }^{1}$ Dimitrios A. Andreadis, ${ }^{2}$ Alexandros L. Zografos, ${ }^{3}$ Hamde Nazar, ${ }^{4}$ Pavlos Klepetsanis, ${ }^{5}$ Susanna M. van der Merwe, ${ }^{6}$ Dimitrios G. Fatouros ${ }^{1, *}$

${ }^{1}$ Laboratory of Pharmaceutical Technology, Department of Pharmaceutical Sciences, Aristotle University of Thessaloniki, GR-54124 Thessaloniki, Greece

${ }^{2}$ Department of Oral Medicine / Pathology, School of Dentistry, Aristotle University of Thessaloniki, GR-54124 Thessaloniki, Greece

${ }^{3}$ Laboratory of Organic Chemistry, Department of Chemistry, Aristotle University of Thessaloniki, GR-54124 Thessaloniki, Greece

${ }^{4}$ School of Medicine, Pharmacy and Health, Durham University, Holliday Building, Queen's Campus, Stockton on Tees, TS17 6BH, UK

${ }^{5}$ Laboratory of Pharmaceutical Technology, Department of Pharmaceutical Sciences, University of Patras, GR-26504 Patras, Greece

${ }^{6}$ School of Pharmacy and Biomedical Sciences, University of Portsmouth, St. Michael's Building, White Swan Road, Portsmouth PO1 2DT, UK

${ }^{*}$ Corresponding author: Dr Dimitrios G. Fatouros e-mail: dfatouro@pharm.auth.gr Tel: +30 2310997653

Fax: +30 2310997652 


\section{Abstract}

In the current study the ex vivo permeation of ropinirole hydrochloride (RH) across porcine buccal mucosa in the presence of three permeation enhancers namely; $\mathrm{N}$ trimethyl chitosan (TMC) (positively charged) a chitosan derivative, sulfobutyl ether$\beta$-cyclodextrin (SBE- $\beta$-CD) (negatively charged) and hydroxypropyl- $\beta$-cyclodextrin (HP- $\beta-C D)$ (neutral), was investigated. Buccal permeation studies were conducted using Franz diffusion cells. Cumulative amounts of RH were plotted versus time. The presence of the permeation enhancers significantly increased the transport of the drug across the porcine buccal epithelium compared to its plain congener (RH solution). The rank order effect of the permeation enhancers for the transport of $\mathrm{RH}$ across buccal epithelium was TMC $\geq$ SBE- $\beta$-CD $>$ HP- $\beta-\mathrm{CD}>\mathrm{RH}$ solution. The presence of TMC increased 1.34 fold the transport of RH across buccal epithelium whereas an increase of 1.23 and 1.28 fold was reported in the presence of HP- $\beta-C D$ and SBE- $\beta-C D$. Infrared spectroscopy (IR) was employed to investigate the interaction of permeation enhancers with the epithelial lipids of porcine buccal mucosa corroborating the permeation results. Finally light microscopy was performed to assess the histological changes in the porcine epithelium. Formation of vacuoles, spongiosis and acantholysis linear detachment and destruction of the epithelium resulted from the presence of the permeation enhancers. The data suggest that all enhancers tested, and particularly TMC, increase the transport of $\mathrm{RH}$ across buccal epithelium.

Keywords: ropinirole hydrochloride; Parkinson's disease; buccal delivery; permeation enhancers.

\section{Introduction}


The buccal route offers many advantages over conventional routes of drug delivery with an improved bioavailability at smaller doses than oral formulations due to the avoidance of degradation in the gastrointestinal tract and hepatic first-pass metabolism [1]. Drugs can reach the systemic circulation directly through the capillary vessels, bypassing the first-pass metabolism in the intestine and liver or avoiding inactivation in the stomach. These characteristics contribute to higher bioavailability parameters after administration of a smaller dose of the drug than in conventional oral formulations [2]. An approach to overcome the barrier properties of the buccal mucosa for drugs is the incorporation of chemical enhancers in the formulations [3,4]. Bile salts, cyclodextrins and chitosan are commonly used enhancers. Methyl- $\beta$ - and $\beta$-cyclodextrins have been previously evaluated for their potential enhancement effect on the buccal permeation of omeprazole [5]. Chitosan [6] and its derivatives [7, 8] have also showed a significant enhancing effect on permeation of drugs across the buccal mucosa.

In an attempt to investigate the effect of charge to the transport rate of ropinirole hydrochloride $(\mathrm{RH})$ and any effect at the ultrastructure of the tissue three permeation enhancers, namely $\mathrm{N}$-trimethyl chitosan (positively charged) a chitosan derivative, sulfobutyl ether- $\beta$-cyclodextrin (SBE- $\beta$-CD) (negatively charged) and hydroxypropyl$\beta$-cyclodextrin (HP- $\beta$-CD) (neutral) were investigated. RH is a dopamine non-ergoline agonist for Parkinson's disease therapy undergoing extensive first-pass metabolism; therefore might be a good candidate for buccal administration [9-12].

Porcine buccal mucosa, being a non-keratinized epithelium and strongly supplied with blood by a dense capillary vessel network, has been used as model membrane because its morphology and permeability are comparable to that of human buccal epithelium $[13,14]$. Buccal permeation studies were conducted using Franz diffusion cells. Infrared spectroscopy (IR) was employed to investigate the interaction of permeation 
enhancers with the epithelial lipids of porcine buccal mucosa. Finally light microscopy was performed to assess the histological changes resulting from the presence of the permeation enhancers.

\section{Materials and methods}

\subsection{Materials}

Ropinirole $\mathrm{HCl}$ was kindly supplied by Pharmathen SA, Greece. Sulfobutyl ether- $\beta$ cyclodextrin (SBE- $\beta-C D)$ and hydroxypropyl- $\beta$-cyclodextrin $(\mathrm{HP}-\beta-\mathrm{CD}) \mathrm{KLEPTOSE}^{\circledR}$ were purchased from Roquette (Lestrem, France) Captisol ${ }^{\circledR}$ (La Jolla, USA) with MW 2170 and $1400 \mathrm{~g} / \mathrm{mol}$ respectively. Methanol $(\mathrm{MeOH})$ was purchased from Chem-Lab NV (Belgium) and $\mathrm{CH}_{3} \mathrm{COONH}_{4}(\mathrm{MW}$ 77.08) from Panreac Quimica SA (Spain). Buffer pH 6.8 solution simulating saliva was prepared using $\mathrm{NaCl}(0.85 \mathrm{~g}), \mathrm{Na}_{2} \mathrm{HPO}_{4}$ $(0.20 \mathrm{~g})$ and $\mathrm{NaH}_{2} \mathrm{PO}_{4} .2 \mathrm{H}_{2} \mathrm{O}(0.13 \mathrm{~g})$ in $100 \mathrm{~mL}$ of distilled water. Phosphate buffered saline (PBS) pH 7.4, was prepared by dissolving $\mathrm{NaCl}$ (8.0g), $\mathrm{KCl}(0.20 \mathrm{~g}), \mathrm{Na}_{2} \mathrm{HPO}_{4}$ (1.44 g), and $\mathrm{KH}_{2} \mathrm{PO}_{4}(0.24 \mathrm{~g})$ in $1 \mathrm{~L}$ of distilled water. Low molecular weight (LMW, $150 \mathrm{kDa}$, DD 95 - $98 \%$ ) chitosan was obtained from Fluka UK. Methyl iodide and 1methyl-2-pyrrolidinone were obtained from Across Organics, Belgium. All chemicals and solvents were of analytical grade and all components of buffer solutions were purchased from Merck (Germany).

\subsection{Trimethylchitosan synthesis and characterisation}

Chitosan polymer were reductively methylated to form TMC polymers with low degree of quaternisation according to the method of Sieval et al. [15]. Briefly chitosan (2.0 g) and sodium iodide (4.8 g) were dissolved in N-methyl-2-pyrrolidinone ( $80 \mathrm{~mL}$ ) on a water bath at $60{ }^{\circ} \mathrm{C}$ under stirring. Sodium hydroxide $(11 \mathrm{~mL}, 15 \% \mathrm{w} / \mathrm{v})$ and methyl 
iodide $(11.5 \mathrm{~mL})$ were added when the chitosan was fully dissolved and the reaction was left stirring for $1 \mathrm{~h}$ at $60{ }^{\circ} \mathrm{C}$ in the presence of a Liebig condenser. The polymer products were then collected by precipitation with ethanol and ether and isolated by centrifugation using a Jouan B4i centrifuge (Thermo Electron Corporation, Waltham, USA). The products were washed twice with ethanol and diethyl ether to yield $\mathrm{N}$ trimethylchitosan iodide with a low degree of quaternisation. Ion exchange was undertaken by dissolving the product in sodium chloride $(40 \mathrm{~mL}, 10 \% \mathrm{w} / \mathrm{v})$.

The product was again precipitated with ethanol and diethyl ether and isolated by centrifugation to yield a white powder, which was subsequently dissolved in deionized water $(40 \mathrm{~mL})$ and filtered using a dialysis membrane to remove any residual sodium chloride. The solution was then freeze dried using a Modulyo Freeze dryer (Thermoelectron Corporation, Waltham, USA) to yield N-trimethyl chitosan chloride with low degree of quaternisation (LDQ).

The ${ }^{1} \mathrm{H}-\mathrm{NMR}$ spectrum was recorded in $\mathrm{D}_{2} \mathrm{O}, 80{ }^{\circ} \mathrm{C}$ with an Agilent DD2, $500 \mathrm{MHz}$ spectrometer equipped with an NMROne probe.

\subsection{Tissue preparation and transport studies}

Fresh porcine mucosal specimens were obtained from a local slaughterhouse. After killing the animals, the tissue was immediately removed and transported to the laboratory in ice-cold buffer (PBS). The lag time between tissue isolation and start of the experiment was approximately $30 \mathrm{~min}$. The specimens were surgically treated, using scalpel and scissors, to remove excesses of connective and adipose tissue. The thickness of the tissues was measured using a micrometer and the thickness of slices ranged from 650 to $800 \mu \mathrm{m}$. 
Buccal tissues were mounted in Franz diffusion cells with a diffusion area of $4.9 \mathrm{~cm}^{2}$ and a compartment volume of $15 \mathrm{~mL}$. After an equilibration period of $10 \mathrm{~min}$ with PBS on both sides, the acceptor compartment was filled with the PBS pH 7.4 and the donor compartment with $5 \mathrm{mg} / \mathrm{mL}$ of $\mathrm{RH}$ plain solution or in presence of $0.05 \%$ (w/v) of the water-soluble enhancers [TMC (5\% w/v in water), SBE- $\beta-\mathrm{CD}(70 \% \mathrm{w} / \mathrm{v}$ in water at $\left.25^{\circ} \mathrm{C}\right), \mathrm{HP}-\beta-\mathrm{CD}\left(50 \% \mathrm{w} / \mathrm{v} \mathrm{g} /\right.$ in water at $\left.\left.25^{\circ} \mathrm{C}\right)\right]$ in $1 \mathrm{~mL}$ of $\mathrm{PBS} \mathrm{pH} 6.8$. The diffusion studies were carried out at $37^{\circ} \mathrm{C}$, under stirring. At regular time intervals, samples of $1 \mathrm{~mL}$ were taken from the acceptor compartment and were replaced with the same amount of fresh buffer solution. Each experiment was carried out for 5 hours and results are reported as means of six different repetitions.

\subsection{Sample analysis}

Upon their collection the samples were centrifuged for 10 minutes at 12,000 rpm, the supernatant was collected and further evaporated to dryness by heating at $80{ }^{\circ} \mathrm{C}$. The dried samples were reconstituted by adding $1 \mathrm{~mL}$ of mobile phase.

Drug content was quantified using an HPLC system consisting of a LC-10 AD VP pump, an autosampler model SIL-20A HT equipped with a $100 \mu \mathrm{L}$ loop and a UV-Vis detector model SPD-10A VP (SHIMADZU) using a MZ-Analytical Kromasil C18 250 $\mathrm{x} 4 \mathrm{~mm}, 5$ micrometres. UV detector was set at $250 \mathrm{~nm}$ for the detection of ropinirole hydrochloride. The mobile phase consisted of methanol-ammonium acetate $10 \mathrm{mM} \mathrm{pH}$ 4.5 in ratio $\mathrm{MeOH}: \mathrm{CH}_{3} \mathrm{COONH}_{4}$ 90:10 (v/v). The adjustment of $\mathrm{pH}$ was done with $1 \mathrm{M}$ solution of $\mathrm{CH}_{3} \mathrm{COOH}$. Flow rate was set at $0.9 \mathrm{~mL} / \mathrm{min}$ and the injection volume at $90 \mu \mathrm{L}$. The HPLC assay was performed at ambient temperature. All solvents were filtered through a $0.45 \mu \mathrm{m}$ nylon membrane and degassed prior to use. The retention 
time was 3 min. A good linearity $\left(r^{2}=0.999\right)$ was established in the range of $0.5-10$ ppm.

\subsection{Analysis of permeation data}

The steady state flux $\left(J_{s}\right)$ across the epithelium were calculated using the following equation,

$$
J_{s}=\mathrm{Q} / \mathrm{A} \mathrm{t}\left(\mu \mathrm{g} / \mathrm{cm}^{2} \mathrm{hr}\right)(1)
$$

where $\mathrm{Q}$ is the cumulative amount of drug penetrating the mucosa $(\mu \mathrm{g}), \mathrm{A}$ is the diffusional area $\left(\mathrm{cm}^{2}\right)$ and $\mathrm{t}$ is the total time of the experiment $(\mathrm{h})$.

The permeability coefficient $(\mathrm{P})$ was then calculated according to the following equation,

$$
\mathrm{P}=J_{s} / \mathrm{C}_{\mathrm{d}}(\mathrm{cm} / \mathrm{hr})(2)
$$

where $C_{d}$ is the drug concentration in the donor compartment.

In order to normalize the permeability data in the presence of the enhancer compared to control, enhancement ratios (ER) were calculated according to equation (3),

$$
\mathrm{ER}=\mathrm{P}_{\mathrm{enh}} / \mathrm{P}_{\text {control }}
$$

where $\mathrm{P}_{\mathrm{enh}}$ is the permeability coefficient corresponding to the enhancer treated epithelial tissues, and $\mathrm{P}_{\text {control }}$ is the permeability coefficient respectively for the control (RH solution).

\subsection{Infrared Spectroscopy}

Infrared spectroscopy (IR) was employed to investigate the interaction of permeation enhancers with the epithelial lipids of porcine buccal mucosa. At the end of each 
experiment, pieces of tissue were soaked in PBS for ca. $10 \mathrm{sec}$ to rinse the enhancers from the mucosal surface and then placed in a dessicator for drying. Intact (untreated) buccal tissue epithelium was used as the control. Analysis of the samples was carried using a spectrophotometer ATR-FTIR (Prestige-21, SHIMADZU) in the range between 4000 and $650 \mathrm{~cm}-1$ with a resolution of $4 \mathrm{~cm}^{-1}$ after 64 scans.

\subsection{Histological evaluation}

Abnormalities of the mucosal architecture after drug and chemical enhancers and nontreated buccal epithelium, were evaluated using $4 \mu \mathrm{m}$-thick sections of each of the formalin-fixed and paraffin-embedded samples stained by conventional hematoxylineosin. Specimens were analysed in an Olympus CX31 optical microscope and microphotographs were taken via the OLYMPUS analysis getIT software.

\subsection{Statistical analysis}

The results are presented as mean \pm standard deviation of 6 experiments. Statistical differences were tested using unpaired Student t-test $(\mathrm{p}<0.05)$.

\section{Results and Discussion}

\subsection{Determination of degree of quartenisation}

The degree of quaternisation of TMC polymer from the 1H-NMR spectrum (Figure 1) was calculated from Eq. 4,

$$
\mathrm{DQ}(\%)=[(\mathrm{TM} / \mathrm{H}) \times 1 / 9] \times 100(4)
$$

where DQ $(\%)$ is the degree of quaternisation expressed as a percentage, TM is the integral of the trimethyl amino group $\left(\mathrm{N}\left(\mathrm{CH}_{3}\right)_{3}\right)$ peak at $3.3 \mathrm{ppm}$ and $\mathrm{H}$ is the integral of the ${ }^{1} \mathrm{H}$ peaks between 4.7 and 5.7 ppm. From Eq. 1 the degree of quaternisation of 
chitosan was calculated at $17-18 \%$ which is in broad agreement with previous studies [16].

\subsection{Transport studies}

Permeation profiles of plain drug and its permeation enhancement congeners, expressed as the cumulative amount permeated versus time, are shown in Figure 2. The steady state flux $\left(J_{S}\right)$ across the epithelium, the permeability coefficient $(\mathrm{P})$ and the enhancement ratios are illustrated at Table 1 . The cumulative amount of RH in the presence of TMC transported across buccal epithelium over $5 \mathrm{~h}$ was only 1.34 -fold (ttest $\mathrm{p}<0.05)$ greater compared to the control $(\mathrm{RH}$ solution). In the presence of SBE- $\beta$ $\mathrm{CD}$ the increase of transported drug was 1.28 (t-test $\mathrm{p}<0.05$ ) higher compared to the control. In a similar manner in the presence HP- $\beta-C D$ the amount of RH transported across buccal epithelium increased 1.23 (t-test $\mathrm{p}<0.05)$ compared to the control (solution of RH). However there was no significant difference to the transported drug between TMC and SBE- $\beta$-CD (t-test $\mathrm{p}>0.05$ ). The rank order effect of the permeation enhancers for the transport of $\mathrm{RH}$ across buccal epithelium was the following: TMC $\geq$ SBE- $\beta$-CD $>$ HP- $\beta$-CD $>$ RH solution.

In a previous study the enhancing properties of TMC for the buccal delivery of a model macromolecular permeate (FITC-Dextran $4.4 \mathrm{kDa}$ ) have been attributed to partial dismantling of the structure of the extracellular matrix and intercellular joints which in turn weakens the epithelium barrier [7]. The enhanced ratios compared to the control in the presence of the cyclodextrins could be attributed to the fact that these oligosaccharides can permeate biomembranes, interacting with the lipids and increasing drug uptake through the epithelium $[17,18]$. 


\subsection{Infrared spectroscopy analysis}

Although buccal mucosa represents a non-cornified epithelia, these typical $\mathrm{CH}_{2}$ bands have already been reported for buccal mucosa in FTIR spectra [4, 19]. Of particular interest are the peaks near 2854 and $2918 \mathrm{~cm}^{-1}$ (Figure 3A). After treatment with the enhancers, stretching vibrations were broadened but no significant shift was observed. The areas under the $\mathrm{CH}_{2}$ symmetric and asymmetric stretching absorbance were calculated as illustrated in Figure 3B. When the tissue was treated with RH and neutral HP- $\beta-C D$ a decrease to the areas of the symmetric and asymmetric peak were observed compared to the control. However striking differences compared to untreated tissue were recorded in the presence of negatively charged SBE- $\beta-C D$ and positively charged TMC where these peaks vanish implying alterations to epithelial lipid structure and organization. The enhancing action of TMC of SBE- $\beta-\mathrm{CD}$ for the transport of RH might be related with possible solubilization of intercellular lipids.

\subsection{Histopathology data}

Light microscopy was performed to assess the histological changes resulting from the presence of the permeation enhancers. In the histological analysis tissue specimens were treated with plain $\mathrm{RH}, \mathrm{RH} / \mathrm{TMC}, \mathrm{RH} / \mathrm{SBE}-\beta-\mathrm{CD}$ and $\mathrm{RH} / \mathrm{HP}-\beta-\mathrm{CD}$ and were compared to normal oral porcine non-keratinized buccal mucosa. Specimens were analysed in an optical microscope (Olympus CX31). When comparing the normal buccal non-keratinized epithelium (Figure 4A) with the RH treated tissue, epithelial disarray, gap formation as well as moderate detachment of the total epithelium could be identified for the latter (Figure 4B). In contrast, buccal non-keratinized epithelium after 5h treatment with $\mathrm{RH}$ and TMC revealed an increase of epithelium thickness, epithelial detachment and mild acantholytic alterations (gaps) (Figure 4C). Previous 
studies have shown that an increase in intercellular space and swelling is related with increased permeation rates of the active [4]. The current histological finding correlates well with the increased permeation data obtained for RH in the presence of TMC. The most severe epithelial damage was observed for the RH/SBE- $\beta$-CD treatment with intense cellular vacuolation and oedema, necrosis of superficial epithelial layers, intercellular gaps (spongiosis - acantholysis) and mild but clear disarray of basal layer of epithelial cells and subsequent detachment of epithelium from the underlying stroma

(Figure 4D \& E). Similar but less severe alterations were found in case of RH/HP- $\beta$ CD. The latter might be attributed to the non-ionic character of HP- $\beta-C D$. The loss of the superficial cell layers might imply interactions between the cyclodextrins and the epithelial lipids given that cyclodextrins can induce lipid solubilization [20]. However it should be noticed that although the presence of the permeation enhancers induce changes to the ultrastructure of buccal epithelium, the latter are not irreversible.

\section{Conclusions}

The data from the current study demonstrate that the transport of $\mathrm{RH}$ across buccal epithelium is substantially increased by co-administration of permeation enhancers. The highest fluxes observed in the presence of the positively charged enhancer TMC combined with the minor structural changes to the epithelium, may be a promising approach to increase RH through buccal mucosa using different dosage forms (e.g. films, xerogels) [21,22]. Considering that buccal epithelium is permselective [23], with proper manipulation of the membrane, favorable conditions might be created for the transport of charged drugs (e.g. morphine sulfate, atenolol hydrochloride)

\section{Acknowledgements}

The authors would like to thank P. Anastasiadou for her valuable technical support. 


\section{References}

[1] M.E. de Vries, H.E. Boddé, J.C. Verhoef, H.E. Junginger HE, Developments in buccal drug delivery. Crit. Rev. Ther. Drug Carrier Syst. 8(3) (1991) 271 - 303.

[2] G. Campisi, C. Paderni, R. Saccone, O. Di Fede, A. Wolff, L.I. Giannola, Human buccal mucosa as an innovative site of drug delivery. Curr. Pharm. Des. 16 (6) (2010) $641-652$

[3] A.J. Hoogstraate, S. Senel, C. Cullander, J.Verhoef, H.E.Junginger, H.E.Bodde, Effects of bile salts on transport rates and routes of FITC-labelled compounds across porcine buccal epithelium in vitro. J. Control. Release 40 (3) (1996) 211 - 221.

[4] S. Senel, Y. Capan, M.F. Sargon, G. Ikinci, O. Solpan, O. Guven, H.E. Bodde, A.A. Hincal, Enhancement of transbuccal permeation of morphine sulfate by sodium glycodeoxycholate in vitro. J. Control. Release 45 (2) (1997) 153 -162.

[5] A. Figueiras, J. Hombach, F.Veiga, A. Bernkop-Schnürch, In vitro evaluation of natural and methylated cyclodextrins as buccal permeation enhancing system for omeprazole delivery. Eur. J. Pharm. Biopharm. 71 (2) (2009) 339 - 345.

[6] I.Ayensu, J.C.Mitchell, J.S.Boateng, Development and physico-mechanical characterisation of lyophilised chitosan wafers as potential protein drug delivery systems via the buccal mucosa. Colloids Surf. B Biointerfaces. 91 (2012) 258 - 265.

[7] G. Sandri, S. Rossi, M.C. Bonferoni, F. Ferrari, Y. Zambito, G. Di Colo, G., C. Caramella, Buccal penetration enhancement properties of $\mathrm{N}$-trimethyl chitosan: Influence of quaternization degree on absorption of a high molecular weight molecule. Inter. J. Pharm. 297 (1-2), (2005) 146 -155.

[8] N. Langoth, H. Kahlbacher, G. Schöffmann, I. Schmerold, M. Schuh, S. Franz, P. Kurka, A. Bernkop-Schnürch, Thiolated chitosans: design and in vivo evaluation of a 
mucoadhesive buccal peptide drug delivery system. Pharm. Res. 23 (3) (2006) 573 579.

[9] I.F. Tulloch, Pharmacologic profile of ropinirole. Neurology 49 (1 Suppl 1) (1997) S58 - S62.

[10] A.J. Matheson, C.M. Spencer, Ropinirole. A review of its use in the management of Parkinson's disease. Drugs 60 (1) (2000) 115 - 137.

[11] M. Contin, P. Martinelli, Pharmacokinetics of levodopa. J. Neurol. 257 (Suppl 2) (2010) S253 - S261.

[12] J.E. Ahlskog, Pathological behaviors provoked by dopamine agonist therapy of Parkinson's disease. Physiol. Behav. 104 (1) (2011) 168 - 172.

[13] C.A. Lesch, C.A. Squier, A. Cruchley, D.M. Williams P. Speight, The permeability of human oral mucosa and skin to water. J. Dent. Res. 68 (9) (1989) 1345 - 1349.

[14] I. Diaz Del Consuelo, G. Pizzolato, F. Falson, R.H. Guy, Y. Jacques, Evaluation of pig esophageal mucosa as a permeability barrier model for buccal tissue. J. Pharm. Sci. 94 (12) (2005) 2777 - 2788.

[15] A.B. Sieval, M. Thanou, A.F. Kotzé, J.C. Verhoef, J. Brussee, H.E. Junginger, Preparation and NMR characterization of highly substituted N-trimethyl chitosan chloride. Carbohydr. Polym. 36 (2-3) (1998) 157 - 165.

[16] J.H. Hamman, A.F. Kotzé, Effect of the type of base and number of reaction steps on the degree of quaternization and molecular weight of $\mathrm{N}$-trimethyl chitosan chloride. Drug Dev. Ind. Pharm. 27 (5) (2001) 373 - 380.

[17] T. Irie, K. Wakamatsu, H. Arima, H. Aritomi, K. Uekama, Enhancing effects of cyclodextrins on nasal absorption of insulin in rats. Int. J. Pharm. 84 (2) (1992) 129 139. 
[18] M. Masson, T. Loftsson, G. Másson, E. Stefánsson, Cyclodextrins as permeation enhancers: some theoretical evaluations and in vitro testing. J. Control. Release. 59 (1) (1999) $107-118$.

[19] J.C. Schwarz, E. Pagitsch, C. Valenta, Comparison of ATR - FTIR spectra of porcine vaginal and buccal mucosa with ear skin and penetration analysis of drug and vehicle components into pig ear. Eur. J. Pharm. Sci. 50 (5) (2013) 595 - 600.

[20] B. McCormack, G. Gregoriadis, Comparative studies of the fate of free and liposome-entrapped hydroxypropyl-beta-cyclodextrin/drug complexes after intravenous injection into rats: implications in drug delivery. Biochim. Biophys. Acta. $1291(3)(1996) 237-244$.

[21] S. Khan, J.S. Boateng, J. Mitchell, V. Trivedi, Formulation, characterisation and stabilisation of buccal films for paediatric drug delivery of omeprazole. AAPS Pharm.Sci.Tech. 16 (4) (2015) 800 - 810.

[22] J.S. Boateng, J.C. Mitchell, H. Pawar, I. Ayensu, Functional characterisation and permeation studies of lyophilised thiolated chitosan xerogels for buccal delivery of insulin. Protein Pept. Lett. 21(11) (2014) 1163 - 1175.

[23] A. Moscicka-Studzinska, E. Kijeńska, T. Ciach, Electroosmotic flow as a result of buccal iontophoresis-buccal mucosa properties. Eur. J. Pharm. Biopharm. 72 (3) (2009) $595-599$. 
Table 1: Calculated steady state flux values $\left(J_{s}\right)$, permeability coefficients $(\mathrm{P})$ and enhancement ratio for $\mathrm{RH}$ across porcine epithelium in the presence of permeation enhancers.

\begin{tabular}{|c|c|c|c|}
\hline & $J_{s}\left(\mu \mathrm{g} / \mathrm{cm}^{2} \mathrm{~h}^{-1}\right)$ & $\mathrm{P} * 10^{-3}(\mathrm{~cm} / \mathrm{h})$ & ER \\
\hline RH & $18.09 \pm 2.44$ & $3.6 \pm 0.65$ & - \\
\hline RH/TMC & $24.46 \pm 2.11$ & $4.8 \pm 0.74$ & 1.34 \\
\hline $\mathrm{RH} / \mathrm{SBE}-\beta-\mathrm{CD}$ & $22.60 \pm 1.29$ & $4.5 \pm 0.25$ & 1.28 \\
\hline RH/HP- $\beta-C D$ & $21.40 \pm 0.78$ & $4.2 \pm 0.74$ & 1.23 \\
\hline
\end{tabular}

*Values are reported as mean \pm standard deviation $(n=6)$ 


\section{FIGURE LEGENDS}

FIGURE 1: ${ }^{1} \mathrm{H}$-NMR spectrum of N-trimethylchitosan.

FIGURE 2 : Cumulative transport of RH across porcine mucosa: $(\nabla)$ RH solution, $(\Delta)$ in presence of $0.05 \%(\mathrm{w} / \mathrm{v}) \mathrm{TMC},(\bullet)$ in presence of $0.05 \%(\mathrm{w} / \mathrm{v}) \mathrm{SBE}-\beta-\mathrm{CD},(\boldsymbol{\bullet})$ in presence of $0.05 \%(w / v)$ HP- $\beta-C D$.

FIGURE 3 : (A) FT-IR spectra of buccal mucosa (intact), after 5h treatment with plain drug and its co-application with permeation enhancers, (B) Areas under $\mathrm{CH}_{2}$ asymmetric and symmetric stretching absorbance. a: Buccal mucosa (intact), b: treated with RH, c: treated with RH/HP- $\beta-C D$.

FIGURE 4 : Light micrographs of A. porcine buccal mucosa with non-keratinized epithelium (intact), B. Light micrograph of porcine buccal mucosa after 5h treatment with RH. Inter-epithelial gaps (indicated by light blue arrow) and detachment of the epithelium from underlying stroma (black arrow) are illustrated in the micropraph $\mathbf{C}$. Light micrograph of porcine buccal mucosa after $5 \mathrm{~h}$ treatment with RH. Changes to the thickness was noticed and linear detachment of epithelium (indicated by black arrow) with only rare acantholysis (indicated by light blue arrow), D \& E Light micrograph of porcine buccal mucosa after $5 \mathrm{~h}$ treatment with $\mathrm{RH}$ and SBE- $\beta$-CD led to additional severe epithelial damage including intense cellular vacuolation (red arrow) and superficial necrosis (blue arrow), F. Light micrograph of porcine buccal mucosa after 5h treatment with RH and HP- $\beta$-CD showed similar but less severe influence to the epithelial structure compare to RH/SBE- $\beta$-CD treatment. (Magnification x100). 
FIGURE 1

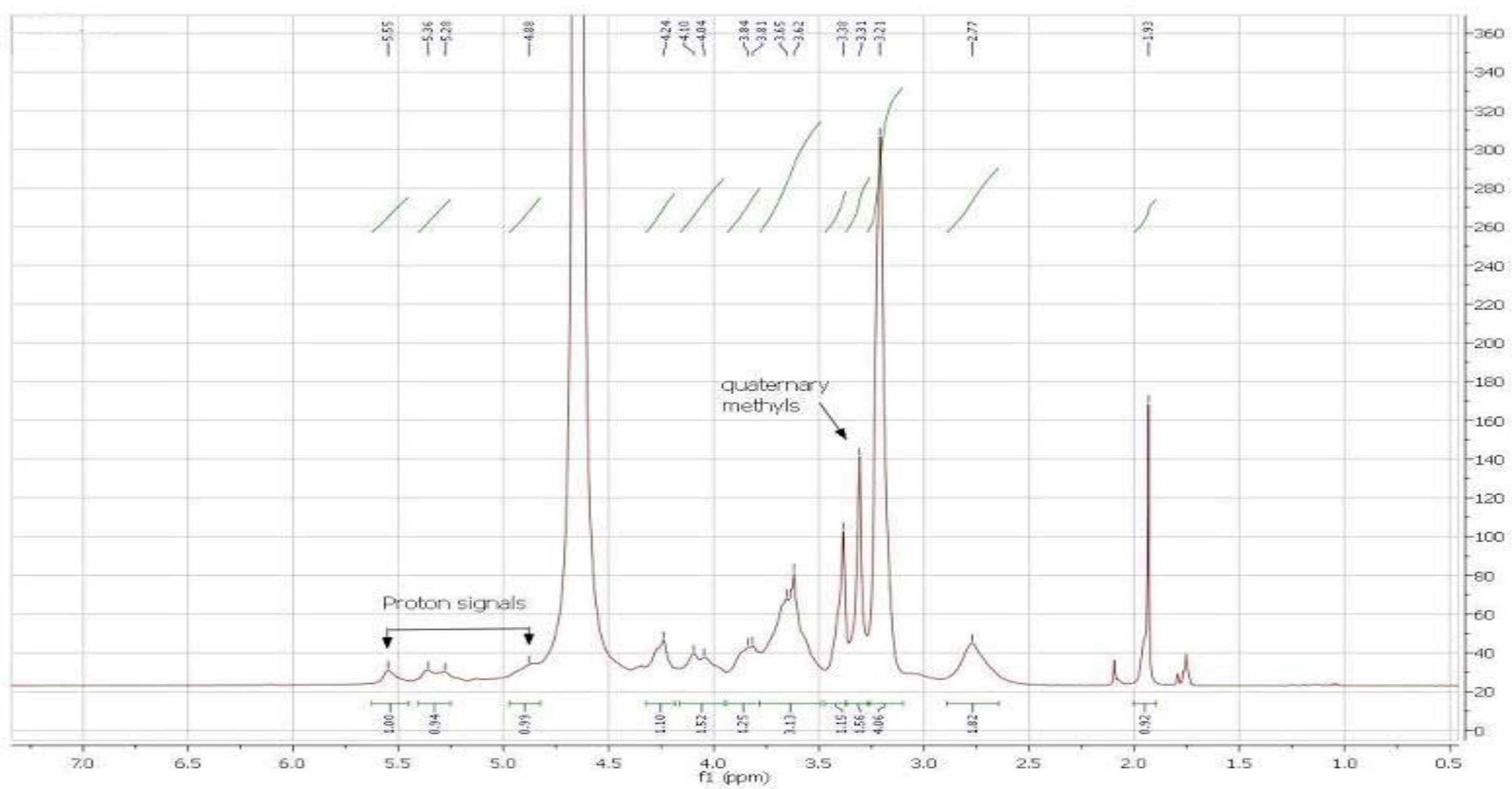


FIGURE 2

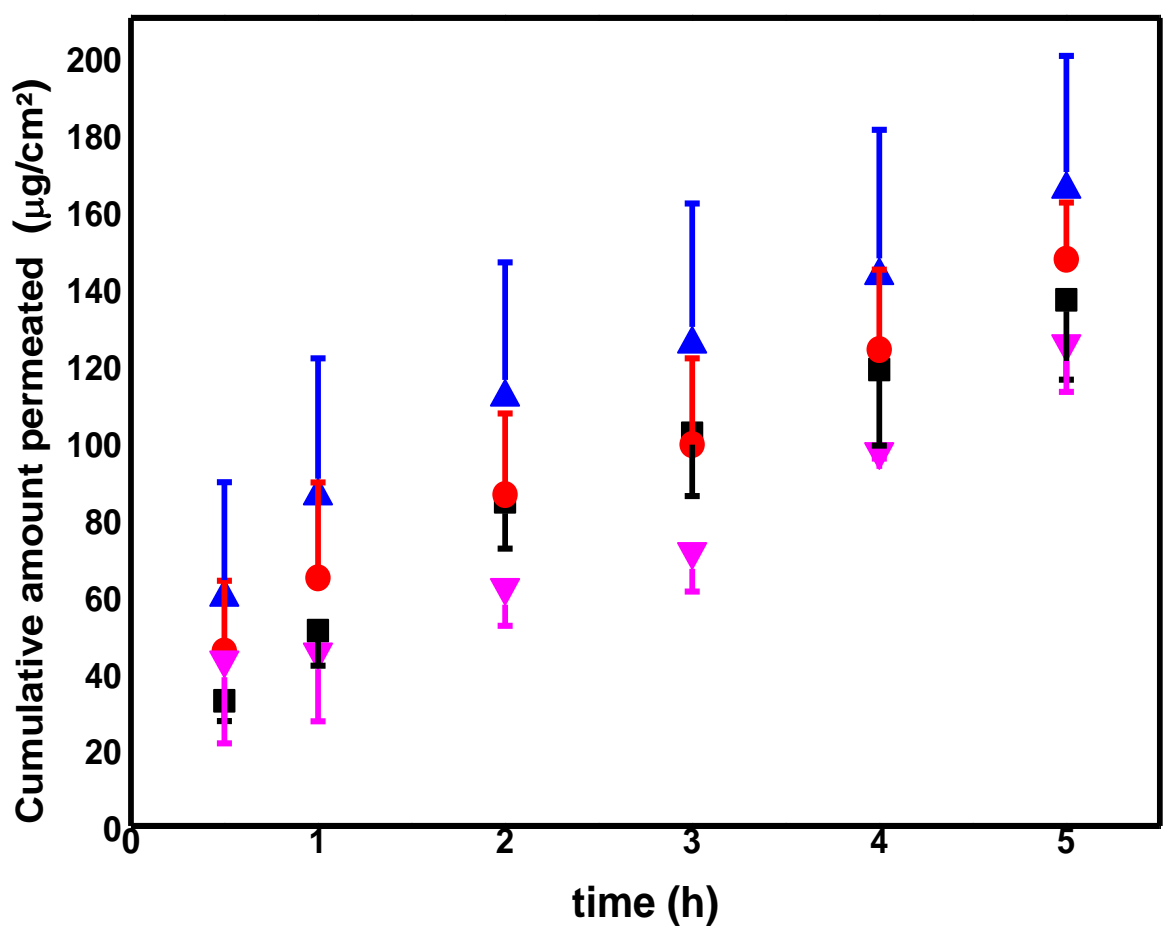


FIGURE 3
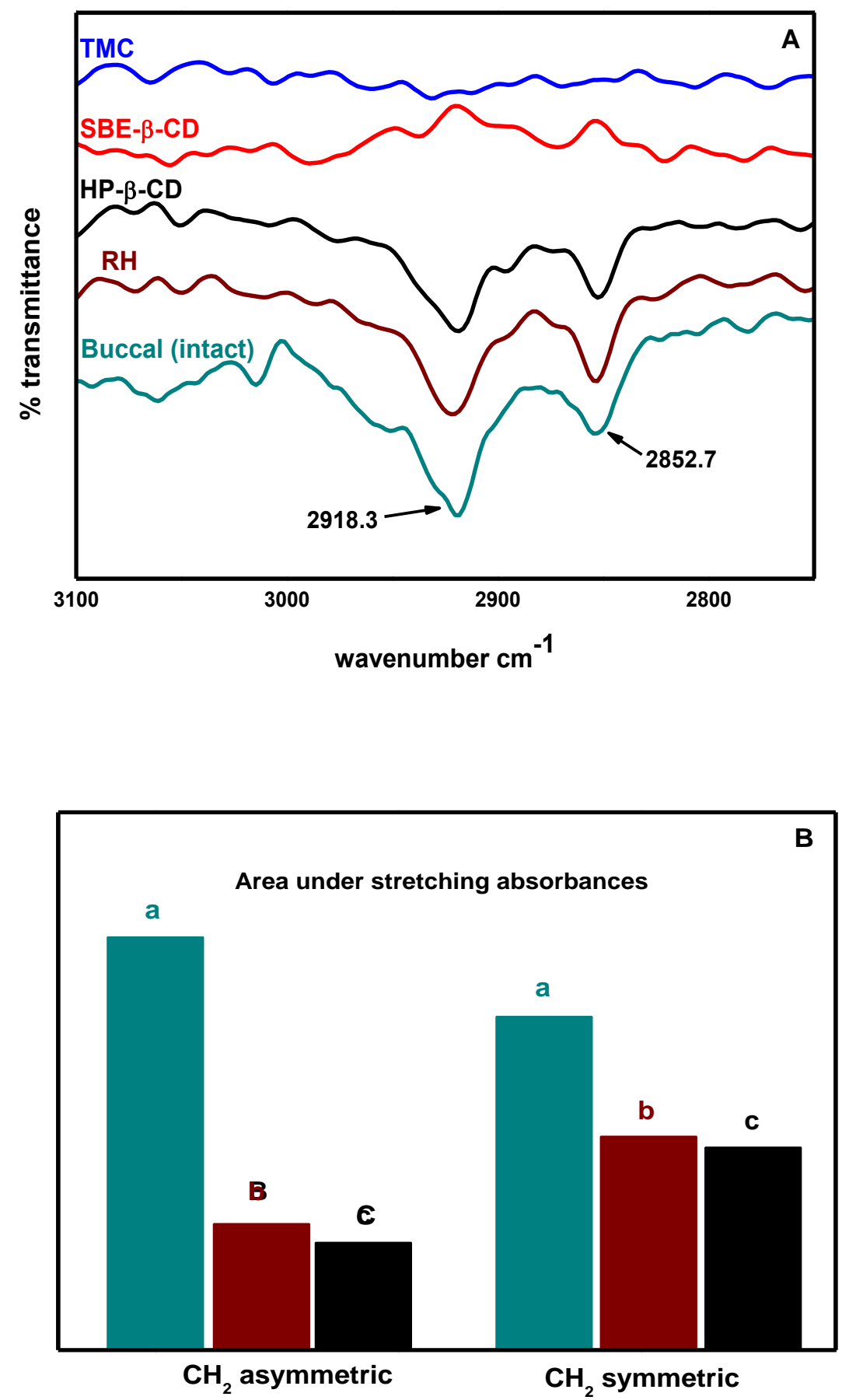
FIGURE 4

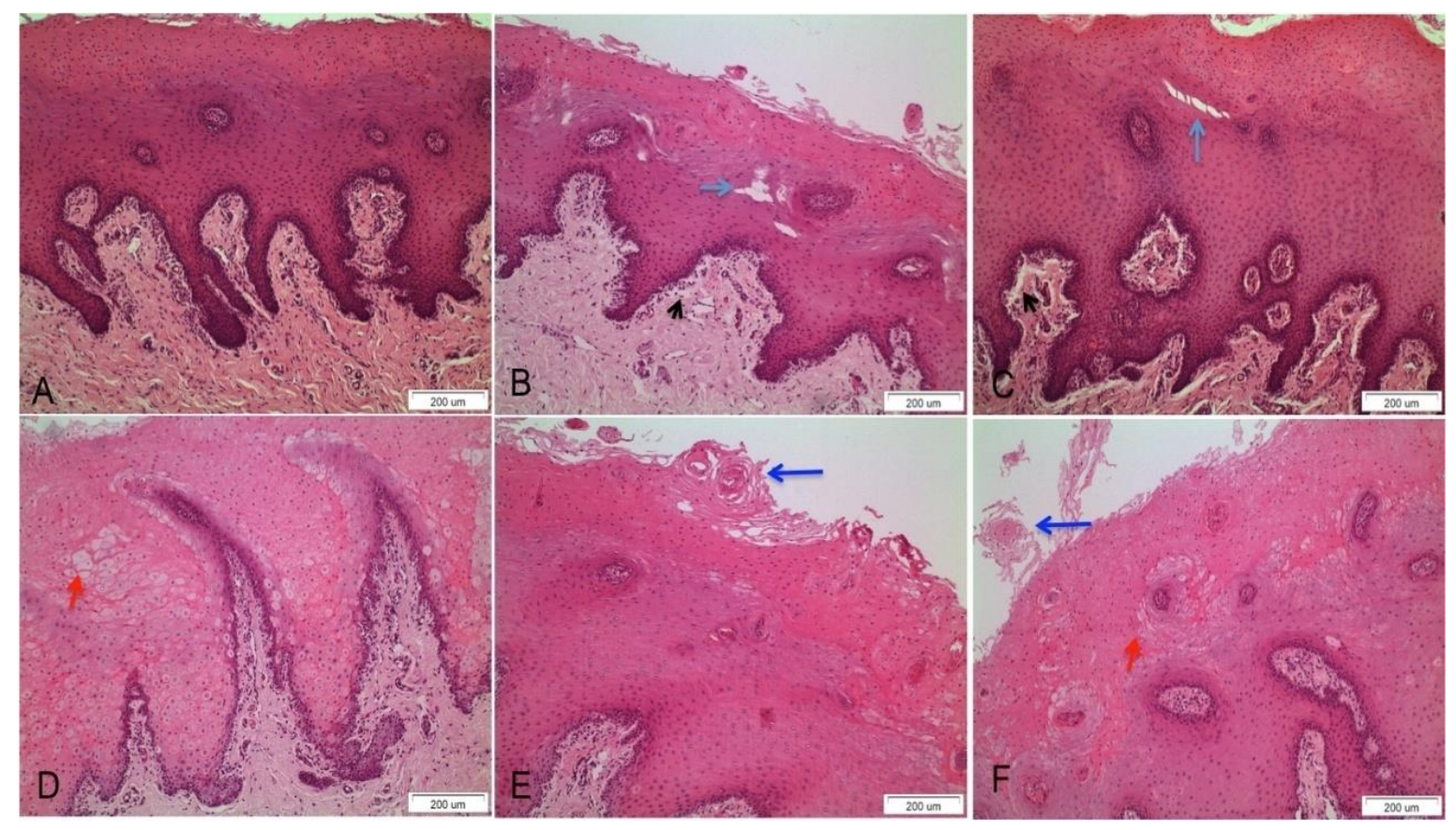

